\title{
Green tea intake and its effect on laboratory parameters and disease symptoms in hospitalised patients with Covid 19: a structured protocol for a randomized controlled trial
}

Sara Mahmoodi ${ }^{1}$, Mojtaba Yousefi ${ }^{1}$, Omid Sadeghi ${ }^{2}$, Ali Mahmoodabadi ${ }^{1}$, Mohammadreza Sadriirani ${ }^{1}$, Zahra Hosseinzade ${ }^{1}$, Abdolhossein Jahanbakhsh' ${ }^{1}$, Seyed Bahman Panahande ${ }^{3^{*}}$ (D), Zaker Saeedinejad ${ }^{4}$, Jan Mohamad Malekzadeh ${ }^{3}$, Mohsen Naghmachi ${ }^{5}$ and Azizollah Pourmahmoudi ${ }^{3}$

\begin{abstract} (ESR), and complete blood count (CBC) in patients with mild-to-moderate Covid-19 infection.

Trial design: Randomized, double-blinded, parallel (1:1 ratio) clinical trial exploratory study Kohgiluyeh and Boyer-Ahmad Province, Iran.

Participants' inclusion criteria are as follows:

Inclusion Criteria

- Patients aged $\geq 18$ years

- COVID-19 diagnosis according to real-time polymerase chain reaction (RT-PCR)

\section{Exclusion Criteria}

- Pregnancy or lactation

- Disseminated intravascular coagulation or any other types of coagulopathy

- Severe congestive kidney failure

- Having a history of participating in a clinical trial during the last 30 days
\end{abstract}

Objectives: The current randomized controlled trial $(R C T)$ will be conducted to assess the effect of green tea intake on disease symptoms and laboratory parameters including C-reactive protein (CRP), erythrocyte sedimentation rate

Participants: We will recruit patients with COVID-19 infection admitted to Yasuj Shahid Jalil Hospital in Yasuj City,

* Correspondence: panahande.b@gmail.com

${ }^{3}$ Assistant Professor of Nutrition, Department of Nutrition, School of Health and nutrition, Yasuj University of Medical Sciences, Yasuj, Iran

Full list of author information is available at the end of the article

(c) The Author(s). 2021 Open Access This article is licensed under a Creative Commons Attribution 4.0 International License, which permits use, sharing, adaptation, distribution and reproduction in any medium or format, as long as you give appropriate credit to the original author(s) and the source, provide a link to the Creative Commons licence, and indicate if changes were made. The images or other third party material in this article are included in the article's Creative Commons licence, unless indicated otherwise in a credit line to the material. If material is not included in the article's Creative Commons licence and your intended use is not permitted by statutory regulation or exceeds the permitted use, you will need to obtain permission directly from the copyright holder. To view a copy of this licence, visit http://creativecommons.org/licenses/by/4.0/ The Creative Commons Public Domain Dedication waiver (http://creativecommons.org/publicdomain/zero/1.0/) applies to the data made available in this article, unless otherwise stated in a credit line to the data. 
Intervention and comparator: Intervention: Two capsules containing $450 \mathrm{mg}$ green tea extract along with routine treatment for COVID-19 patients in the intervention group. Two capsules containing placebo plus routine treatment for patients with COVID-19 infection. Capsules will be taken twice a day, after lunch and dinner, for 14 days.

Main outcomes: Changes in disease symptoms and laboratory parameters including CRP, ESR, and CBC after 14 days of the intervention compared to control group.

Randomisation: Eligible patients will be randomly assigned into the intervention or control group in a 1:1 ratio. Randomization will be performed based on 8 permuted blocks with block sizes of 10, and patients in the intervention and control groups will be matched according to sex and age categories. Randomization will be done using computer-generated random numbers (Randomization.com)

Blinding (masking): The appearance of placebo and green tea capsules will be similar in terms of shape and color, and they will be packed in the same bags that will be prepared by the company. Also, the researcher and all participants will not be aware of the divisions until the end of the study.

Numbers to be randomised (sample size): The total sample was determined based on CRP MCID in which high CRP levels were considered $>2.6 \mathrm{mg} / \mathrm{L}$. Accordingly, a total sample size of 37 patients for each intervention group was required.

Trial Status: The protocol is Version 1.0, on June 5, 2021. Recruitment will start on July 11, 2021, which is anticipated to be completed by September 21, 2021.

Trial registration: IRCT20150711023153N3 (https://www.irct.ir/trial/55948) retrospectively registered on June 4, 2021

Full protocol: The full protocol is attached as an additional file, accessible from the Trials website (Additional file 1). In the interest in expediting dissemination of this material, the familiar formatting was eliminated; this Letter serves as a summary of the key elements of the full protocol.

Keywords: COVID-19, Randomised controlled trial, protocol, ESR, CRP, CBC, green tea supplement

\section{Supplementary Information}

The online version contains supplementary material available at https://doi. org/10.1186/s13063-021-05462-8.

Additional file 1. Full study protocol.

\section{Acknowledgements}

The authors would like to thank the Yasuj University of Medical Sciences for supporting the present research on COVID-19 and thanks to the Dineh company for contributing to this trial and supplying the green tea supplement and placebo.

\section{Authors' contributions}

SBP and MY are the Chief Investigators; they conceived the study. SBP, SM, and MY led the proposal and protocol development. MY, AJ, ZH, SM, MRSI, AM and ZS contribute to data collection, SBP, MY, OS study design, and development of proposal. SBP and SM are revising the manuscript. JMM and AP contributed to statistical interpretations. All authors read and approved the final manuscript.

\section{Funding}

This study was funded and supported by Yasuj University of Medical Sciences, Yasuj, Kohgiluyeh, and Boyer-Ahmad Province, Iran. The funders did not have a role in the design of study, the intervention, collection, analysis, interpretation of data, and writing the manuscript.

\section{Availability of data and materials}

The final dataset of trial will be available upon request from the primary investigator via e-mail at panahande.b@gmail.com, after obtaining permission from Regional Ethics Committee

\section{Declarations}

Ethics approval and consent to participate

Ethics Committee approved the present trial of Yasuj University of Medical Sciences (Ethics Committee Reference Number: IR.YUMS.REC.1400.027) on May 15, 2021. The investigators declare that the trial has received ethical approval from the appropriate ethics committee, as described above. Informed written consent will be obtained from all participants before randomization.

\section{Consent for publication}

Not applicable.

Competing interests

The authors declare that they have no competing interests.

\section{Author details}

${ }^{1}$ Department of Nutrition, School of Health and nutrition, Yasuj University of Medical Sciences, Yasuj, Iran. ${ }^{2}$ Department of Community Nutrition, School of Nutritional Sciences and Dietetics, Tehran University of Medical Sciences, Tehran, Iran. ${ }^{3}$ Assistant Professor of Nutrition, Department of Nutrition, School of Health and nutrition, Yasuj University of Medical Sciences, Yasuj, Iran. ${ }^{4}$ Assistant Professor of Infectious Disease, Department of Internal Medicine, School of Medicine, Yasuj University of Medical Sciences, Yasuj, Iran. ${ }^{5}$ Instructor of Biology, Department of Nutrition, School of Health and Nutrition, Yasuj University of Medical Sciences, Yasuj, Iran.

Received: 28 June 2021 Accepted: 15 July 2021

Published online: 03 August 2021

\section{Publisher's Note}

Springer Nature remains neutral with regard to jurisdictional claims in published maps and institutional affiliations. 